\title{
Epiploic appendagitis: unusual cause of left iliac fossa pain
}

\author{
Ankur Gadodia $\cdot$ Raju Sharma $\cdot$ Rajinder Parshad
}

Received: 21 February 2010 / Accepted: 5 September 2010 /Published online: 22 September 2010

(C) Indian Society of Gastroenterology 2010

A 30-year-old woman presented with acute onset noncolicky pain in left iliac fossa. There were no other associated symptoms. On examination, there was rebound tenderness in the left iliac fossa. Routine blood investigations were normal except mild leukocytosis. CT abdomen revealed a hypodense pericolonic ill-defined mass lesion

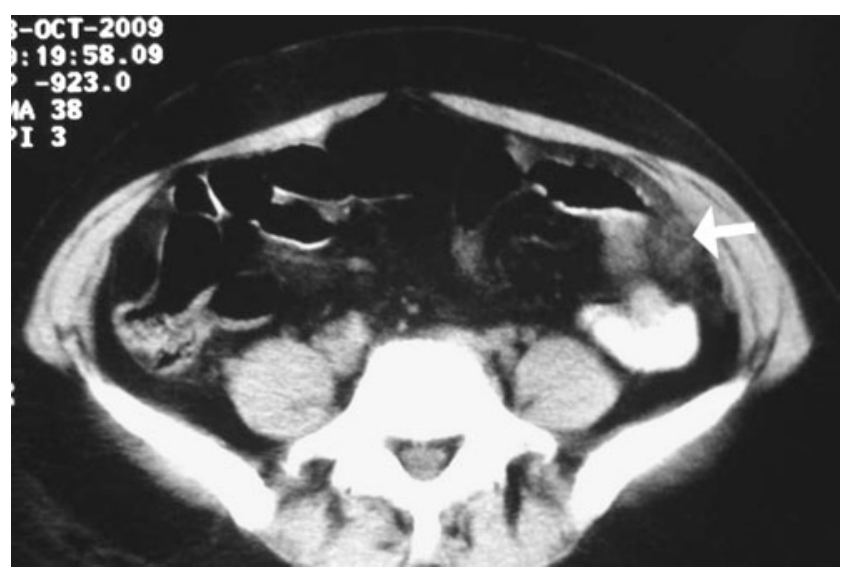

Fig. 1 Axial CT shows an ovoid fat attenuation mass anterior to the colonic wall with adjacent fat stranding (arrow)

\footnotetext{
A. Gadodia $(\triangle) \cdot$ R. Sharma

Department of Radio-diagnosis, All India Institute of Medical Sciences,

New Delhi 110 029, India

e-mail: gadodia_ankur@yahoo.co.in

R. Parshad

Department of Surgery, All India Institute of Medical Sciences, New Delhi 110 029, India
}

with adjacent fat stranding (Fig. 1). Diagnosis of epiploic appendagitis was made. The patient was managed conservatively.

Epiploic appendages are 50-100 pedunculated fatty structures covered by peritoneum over the external aspect of the colon. Involvement of the right colon and cecum is rare [1]; sigmoid colon is more frequently involved. Epiploic appendages are susceptible to torsion and ischemic infarction because of their pedunculated shape and limited blood supply. Ultrasound finding of epiploic appendagitis is a non-compressible hyperechoic mass connected to the adjacent colon at the point of maximum tenderness. CT scan demonstrates an oval fat-attenuating lesion surrounded by a hyperattenuated ring, located near the colon with surrounding fat streakiness and helps in establishing a definite diagnosis [2]. Central dot sign refers to the presence of a central thrombosed vein to the epiploic appendix, and is a specific sign of epiploic appendagitis. However, absence of this sign does not exclude this diagnosis. Differential diagnosis includes acute diverticulitis and appendicitis [3]. Surgery is not required if diagnosis is established on imaging, and most symptoms resolve with conservative management [3].

\section{References}

1. Jain T, Shah T, Juneja S, Tambi R. Primary epiploic appendagitis: radiological diagnosis can avoid surgery. Semin Roentgenol. 2008;43:4-6.

2. Sandrasegaran K, Maglinte DD, Rajesh A, Akisik FM. Primary epiploic appendagitis: CT diagnosis. Emerg Radiol. 2004;11:9-14.

3. Singh AJ, Gervais DA, Hahn PF, Sagar P, Mueller PR, Novelline RA. Acute epiploic appendagitis and its mimics. RadioGraphics. 2005;25:1521-34. 